\title{
The Mantle Record of Crustal
} Evolution

\author{
AlBRECHT W. HOFMANN ${ }^{1}$, IGOR S. PUCHTEL ${ }^{2}$, AND \\ CATHERINE CHAUVEL ${ }^{3}$
}

${ }^{1}$ Max Planck Institute for Chemistry, 55128 Mainz, Germany (albrecht.hofmann@mpic.de)

${ }^{2}$ Department of Geology, University of Maryland, College Park MD 20742, USA (ipuchtel@umd.edu)

${ }^{3}$ IPGP University of Paris CNRS, France 75005 (chauvel@ipgp.fr)

The growth and evolution of the continental crust has been traditionally assessed by the isotopic record preserved in detrital zircons, but translating this record into a continental growth history requires assumptions that are difficult to verify, because most of the early crust, if it ever existed, has been lost to crustal recycling (rather than reworking, which would be reflected by Archean $\mathrm{Nd}$ model ages). An alternative approach is to examine the chemical evolution of the reservoir complementary to the continental crust, namely the mantle. A recent study [1] using $\mathrm{Nb} / \mathrm{U}$ of modern MORB and OIB as a tracer, has shown that the mass fraction of present-day "crust-residual" mantle is $>80 \%$, rather than the $30 \%$ estimate based on $\mathrm{Nd}$ isotopes. We will assume that the residual mantle reservoir was similarly large in Archean time. New, high-precision Nb-Th-U-La data for early and late Archean komatiites show that the mass of continental crust from 3.5 to $2.7 \mathrm{Ga}$ was constant at $\sim 70 \%$ of the present-day crust, as indeed previously suggested by zircon studies [2]. However, the amount of preserved Archean crust is only about $10 \%$ of the total existing crustal volume. This raises the question of what happened to all the missing crustal volume. Recycled ancient crust is found in EM-type OIBs, but the vast majority of OIBs contain little or no recycled continental crust. The uniformity of $\mathrm{Nb} / \mathrm{U}$ in modern MORB and OIB rules out the presence of substantial amounts of recycled continental material in their source, and the $\mathrm{Pb}$ isotopic record of the global MORB array indicates differentiation ages of generally less than $2.0 \mathrm{Ga}$. Similarly, oceanic mantle peridotites do show ancient Re-Os differentiation ages, commonly ranging between 1 and $<3 \mathrm{Ga}$.

The above evidence suggests that mantle convection processes, while preserving many younger mantle heterogeneities, have effectively erased the record of subducted Archean crust by convective homogenization. Whether this is a consequence of a fundamental change in the style of mantle convection or a simple result of the duration of mixing times is currently a matter of debate.

[1] Hofmann, A.W. Class, C., Goldstein (2020) G3 subm.

[2] Dhuime et al. (2012) Science 335, 1334-1336. 